\title{
From the distributed self to the expanded self: gay identity and shifting subject-object positions in online and offline performance
}

\author{
Rian Terblanche and Chris Broodryk* \\ Office 2-11, Drama Building, University of Pretoria, clo Lynnwood Rd \& Roper St, Hillcrest, \\ Pretoria
}

*Corresponding author. Email: Chris.Broodryk@up.ac.za

\begin{abstract}
This study investigates identity construction in online (virtual) and offline (visceral) spaces. Throughout the emphasis is on gay male identity construction. Specifically, the article explores how performance theory can be used to read persona construction in online webcam environments. The mediatory role of online technologies is considered in this regard. In turn, Rian Terblanche's installation-performance owner's MANual to conSEXtualisation is used to discuss how a performance located in a designated physical space demonstrates how such online persona constructions are indicative of constantly shifting subject-object positions, often culminating in what this study refers to as the pornstarification of the persona. This investigation is primarily informed by the work of Turkle and Benedetti, and establishes a link between Turkle's notion of the distributed self and Benedetti's notion of the expanded self as one way to allow online and offline spaces to conceptually speak to one another around gay male identity.
\end{abstract}

Keywords: expanded self; gay masculinity; installation-performance; subject-object positions; pornstarification; virtual/visceral

\section{Introduction}

With its interactional, political and sexual possibilities, the Internet has become an integral part of how individuals construct the world (see Bargh et al. 2002; as well as Matsuba 2006). The World Wide Web has altered the ways in which individuals perceive themselves, creating multiple ways of inhabiting various spaces and engaging with others. By collapsing the boundaries between fact/fiction as well as flesh/machine (Govan et al. 2007, p. 176), new possibilities in creating relationships between online and offline identities have emerged and multiple discourses around the construction of identities have surfaced.

Driven by an interest in tensions between the online and offline, in 2009 I guided the devising and staging of the installation-performance owner's MANual to conSEXtualisation performed from 28 April-2 May 2009 at the Masker Theatre of the University of Pretoria. ${ }^{1}$ The purpose of the production was to explore how theatrical notions of performance can reframe the construction of gay sexual identity within the context of pornographic desire in a virtual gay chat site environment. The ways in which theatrical performance and the theatre space itself may be utilised in order to interrogate how virtual environments (particularly gay webcam chat sites) position and construct gay male identities was interrogated. 
This study aims to investigate how a process of character construction for theatrical performance may inform the performance of the webcam performer on a gay video chat site. To do this, this study examines the relationship between the looking subjects' pornographic desire and the creation of the performer's object position. This study is conducted at the intersection of new media theory, queer theory and theatre (performance) theory in order to optimally address a research question that demands such a multi-angled approach.

\section{Background}

There are numerous male webcam chat sites for gay, bisexual and bi-curious men. ${ }^{2}$ When entering a cam chat room, the user joins a collective of users all inhabiting the same (online) space in connecting and communicating with like-minded individuals. This immediate, collectively shared online (virtual) activity simultaneously happens in an isolated and solitary offline (visceral) space. The offline space plays a significant role in the construction of the online narrative and performance, because of the way the body inhabiting both online and offline environments usually forms the focal point of what is being electronically communicated. Here, interaction occurs via typed text and even video and audio streaming and, consequently, I became curious about the reciprocal effect of this online creation of the profile (or persona) and the offline performance of identities and their gay masculinities.

Amelia Jones (cited in Mowlabocus 2005) argues that 'technology not only mediates but produces subjectivities in the contemporary world'. At the same time, subjectivity is framed by ideology and is discursively constructed (Weedon 2004, p . 9-10). Subjectivity is inextricably linked to identity in that identity constitutes foregrounding a particular mode of subjectivity that temporarily limits who and what a person apparently is. It gives individuals a 'singular sense' of self (Weedon 2004, p . 9 -10). Identity assumes a sense of self-recognition, is relational, and in hetero-patriarchal arenas is created through binary oppositions that assert difference by assigning greater value to one side of the binary than the other (Weedon 2004, p. 19), for example

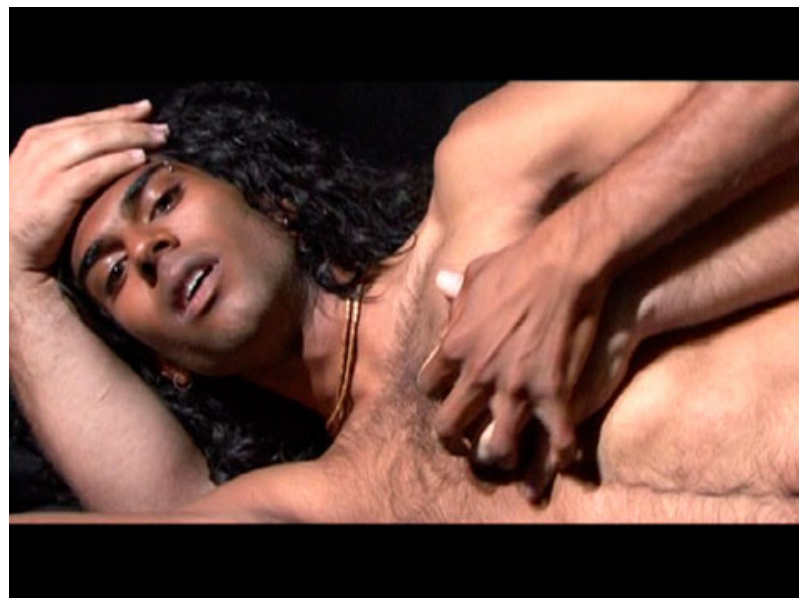

Figure 1. Opening image from teaser trailer used in marketing owner's MANual to conSEXtualisation. The teaser is available at http://www.youtube.com/watch?v $=\mathrm{QXXK2debT5s}$. All images visualised by Rian Terblanche. 
male/female, white/black, straight/gay. The ideological and discursive underpinnings of identities are internalised by individuals to the extent that they become 'naturalised' and a lived expression of a singular, stable, core self. From this point of view, identity is an unfixed construct.

Turkle $(1994,1999,2004,2005)$ discusses the interrelatedness between personal identity construction, subjectivity and cyber technologies in order to understand and interrogate this possible tension between online and offline spaces and explain why it may be possible to use notions of performance to investigate the performance of online gay male identity. Her findings informed the design and construction of the installation-performance owner's MANual to conSEXtualisation: 'We make our objects, and in turn, our objects make and shape us. In the case of computational technologies, we come to see ourselves differently as we catch sight of our images on the mirror of the machine' (Turkle 2004, p. 2). Labelling the computer The Second Self (1984), Turkle argues that the infiltration of technology into our daily lives has not only affected our engagement with the world, but inadvertently altered the way in which we think about ourselves and the various contexts in which we function (Turkle 2005, p. 1). ${ }^{3}$ Computer technologies have bridged the gap between being merely a tool for 'efficiently-getting-things-done', to becoming an integral part of our social and psychological fabric (Turkle 2005, p. 3), enabling us to re-think the 'nature of our sexuality, the form of our communities, thus our very identities' (Turkle 2004, p. 2).

In Cyberspace and Identity (1999), Turkle investigates the significance of role playing as an identity construction endeavour within various cyber spaces. She explains that in these virtual communities, individuals have the freedom to create a persona (or personae) through which they may engage with proximate online collectives. In terms of performance, the concept of the persona may be explained as 'the one who relates the experience in a text' (Lee and Gura 2009, p. 27) to the audience. Although the persona may be a character in the 'story', it is still 'the controlling voice' (Lee and Gura 2009, p. 28) of the narrative and must constantly comment on what is unfolding in front of the eyes of the audience. For the actor interpreting the persona, this idea of constantly commenting on all aspects within the narrative, including himself/herself, foregrounds the notion of the storyteller. The actor is not only an artist able to represent and embody the life of the persona and character (s)he is portraying, but also a storyteller, communicating the story of the character (s)he is representing to the audience. Embodiment of the persona and the character renders him/her as the story itself: '[T]he actor is to consider him[self] as a kind of storyteller whose speciality is that he is the story he is telling' (States 2002, p. 23). Furthermore, the actor must stay in character, as well as to remain 'commentator' (persona) to continually 'point out the significance... of what the character is doing and saying' (McGaw 2011, p. 130). This multiple state of being present for the actor may be compared to Turkle's 'distributed self' $(1999$, p. 644), as it too allows the actor to inhabit and perform different subject positions at the same time, and live and experience a 'decentred identity' (1999, p. 646) through the action of the scene. These personae may transcend sex, gender, race and personality margins and allow these individuals to 'explore different aspects of self, some of which may be insufficiently explored in the physical real' (Turkle 2004, p. 3).

\section{Owner's MANual}

The socio-psychological underpinnings of the above-mentioned personae constructions proved important in the theatre-making process itself (owner's MANual to 


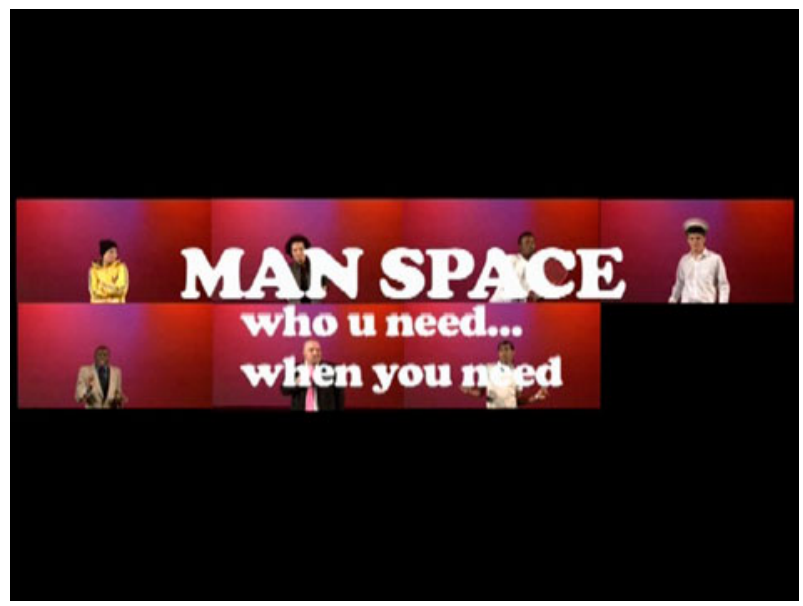

Figure 2. Exploring online persona construction.

conSEXtualisation). The production served as a research space in which the interrogation of the interface between offline and online identity construction could take place. According to Robert L. Benedetti (1981), the actor relies on physical, moral, social and psychological characterisational traits in order to create the dramatic persona. These traits ('Four Levels of Characterisation') form the basis for all actions and purposes of the character and influence effective interaction with all aspects of the play as a whole - the dramatic collective (1981, p. 235-242). Seeing that the actor's only instrument is his/her physical body and total, holistic life experiences, (s)he can only 'explore different aspects of self' (Turkle 2004, p. 3) in order to create the dramatic persona. Benedetti (1981) calls this 'the expanded self. [Y]ou find yourself by reaching at all times out of and beyond yourself; you work on yourself...by simply allowing yourself to become the person who does what is to be done in the scene' (1981, p. 5). The actor and the individual creating an online (virtual) persona, may be exploring similar processes in creating new identities, as will be discussed later.

The theatre space was divided into separate isolated quadrants located offstage in the area traditionally reserved for seating the audience, emphasising the isolation of the individual during these online interactions. The quadrants, physically separated by thin wall-like barriers, were visually and spatially similar, with no unique or individual characteristics to indicate a specific spatio-temporal location. LCD screens were suspended in front of each quadrant. Each quadrant was further outfitted with two 'stations' (computer and webcam) for the actors.

The main focus areas were the 'screens', presenting an online space, but placing the actors behind the 'screen' (in an offline capacity) encouraged the audience to be aware of the visceral and corporeal nature of these digital interactions and the fact that the online and offline occur simultaneously. The actor's body became the primary way for the audience to relate with what was presented within the offline performance space. Manipulating the way in which the viewer perceived this body through the use of technology offered a critical view on how they engage with, and the possible influences of the interaction on, the performance. Incorporating webcams focused on the audience and streamed onto all the screens made the audience aware of their own presence and 
interaction with the digital personas and their influence and participation in their construction. The audience's mediated presence successfully made them 'spectactors' (Boal 1995, p. 13). ${ }^{4}$ Boal explains that the ability to observe oneself in action creates self-knowledge and self-awareness. This insight into the conceptual understanding of the self within various contexts creates an opportunity to become a 'subject of another subject', in this case 'the one who observes...the one who acts' (Boal 1995, p. 13). Both parties (in the Boal context spectator and actor) actively participate in this process of creating themselves and the other, neither becoming just the object to satisfy a need, but also the subject with abilities to act upon the other. In this way the subjects are able to imagine variations and alternatives to their own behaviour which will allow for the construction and physical manifestation of what might be possible (Boal 1995 , p . 13 -14). Hence the notion of the 'spect-actor', because 'the human being not only makes theatre: it "is" theatre' (Boal 1995, p. 13).

The installation-performance, on the other hand, aimed to investigate visually constructed online personae, identities and (gay) masculinities mediated via webcam technologies. Kibby and Costello (2001) maintain that in cyberspace the body concurrently reveals its absence and presence during the online activity. Their study focuses on interactive sex communities and the display of the penis as the signifier of the phallus and 'the construction of a male sexual spectacle' (Kibby and Costello 1999, p. 354). Although the physical body (present) is being broadcasted by the use of video broadcasting software and hardware technologies, its materiality is mediated. The broadcasted or online image of the body is constructed through 'signifiers of the erotic: settings, costumes, props and poses elaborated for erotic purposes' (Kibby and Costello 1999, p. 360), which renders the physical body to a certain extent fabricated.

This mediation of the materiality of the body speaks directly to Turkle's ( 1999, p. 2004) text-based, excision-facilitated process of online personae construction. The possibilities in utilising these various online environments as new 'cybersocial' platforms on which to experiment and experience facets of, and beyond themselves, has created an opportunity 'to perform as members of an opposite or alternative gender, as well as to exploit nonhegemonic sexual performances' (Del Rosso 2011, p. 718). In order to investigate the above through performance, a practice-led research methodology was used.

Performative inquiry as qualitative approach to performance research applies the totality of the human being to investigate the relationship between performance, inquiry and experience. Performative inquiry views knowledge as an act of creation, as 'bringing forth a world... as part of living it' - a process akin to performance (Fels and Meyer 1997, p. 76). Performative inquiry uses the self as raw material for exploration and knowledge creation. It is both phenomenon and method simultaneously.

This interaction between the visceral and the virtual allows me to explore discourses on, and performances of, gay identities in virtual environments that foreground pornography as the key signifier of gay masculinity. Performative inquiry is 'a lens through which [I] engage with the field of study' (Fels 1999, p. 28) and to inform an understanding of gay individuals' identity construction in online pornographic spaces, of performing 'digital flesh' (Govan et al. 2007, p. 176) in owner's MANual to conSEXtualisation.

Although there is a strong focus on the use of technology and new media, the emphasis will still fall on the 'nowness' (Govan et al. 2007, p. 175) of the performance space (whether this space is online or offline). The online existence may to a certain extent be viewed as a theatrical performance allowing the actor/user to perform his own 
identity, where performance is a body-centred act of construction. The performer's body may be seen as the primary way for an audience to relate with what is presented within the offline performance space, but by manipulating the way in which the viewer perceives this mediated body, notions of identity as performance are foregrounded as in line with Butler (1990) and Jones (2002).

\section{The performance of identity}

As previously mentioned, Turkle (2004, p. 3) accentuates the fundamental psychological and social authenticities of these online creations and the corporeal reinforcements these psychosocial aspects bring to identity constructions and explorations. Murray and Sixsmith elaborate by arguing the inevitable transportation of not only the body, 'but also our history and our social and cultural context' (1999, p. 320) into cyberspace, emphasising how cyber technologies enable the individual to "map his or her sense of corporeality directly onto represented virtual forms' (1999, p. 316), but acknowledging that racial, cultural and gender codes and inscriptions on the physical body cannot be eliminated from the online, virtual experience. Like the individual creating online personae and exploring aspects of self which are not always permitted, or accessible, in the offline world (or as Turkle calls it, the 'physical real' [2004, p. 3]), the actor, in exploring an 'expanded self', is also able to explore facets of himself/herself, which may go beyond his/her culturally inscribed codes. In the same way in which Murray and Sixsmith (1999) describe the transportation of the body into cyberspace, the actor has to experience the created persona (character) by mapping his/her personal corporeality onto the actions of the character within the scene.

For the actor, the process of theatrical illusion begins with an impulse. An impulse is a movement forward, towards doing. The image is lodged within the actor's own experience, or within the actor's ability to imagine the experience. The image leads to the physical manifestation of the impulse, action. Action is tangible, malleable, and capable of transformation. (Harrop and Epstein 1996, p . 11 )

The actor relies on his/her epistemological self in order to create a character in a fictional world. ${ }^{5}$ The actor uses his/her understandings of human behaviour through his/her 'culturally constituted body' (Murray and Sixsmith 1999, p. 321) in order to familiarise himself/herself with the new experience(s). The actor may also be required to play several

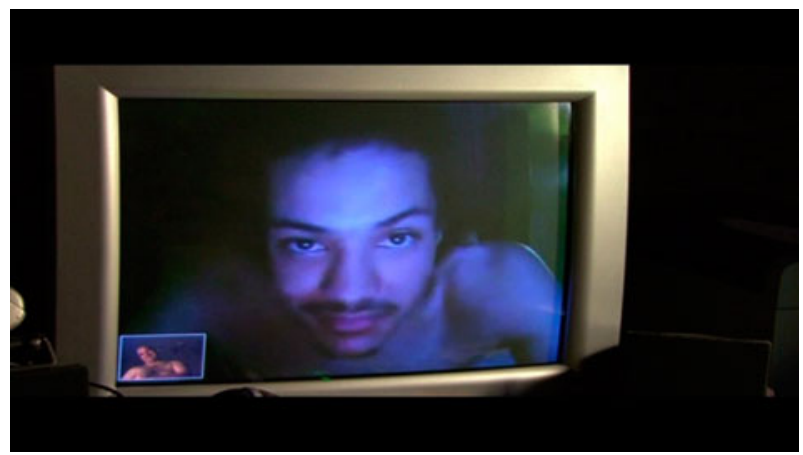

Figure 3. The self as performed in and through technology. 
different roles at the same time and have access to all of them simultaneously. Benedetti refers to this activity as 'your sense of identity' as a 'sense of continuity' that underlies various performances, '[tying] them together into one personality' (1981, p. 6). Benedetti imagines a 'personal space', which is able to function concurrently in different relationships, environments and emotional moments in order to negotiate the demands of the scene.

Similar to the actor being able to access and experience multiple roles in an offline environment, the webcam performer is able to experiment with new identities and aspects of self in cyberspace. In owner's MANual to conSEXtualisation the actors not only had to create the fictional offline character, drawing from their personal backgrounds by applying Benedetti's notion of the 'expanded self', but also had to construct and perform the character's parallel online identity/identities - the persona of the webcam performer. This dyad served to frame the possibilities of the experimentations with multi-distributed selves (online and offline) and guided the explorations of how the theatre performance may be utilised to position the virtual environment as significant role player in the construction of offline and online identities.

Turkle (1999) stresses that, in a technologically advanced world, multiple personae constructed by an individual inhabit the body of their creator, as well as several virtual spaces simultaneously.

Shifting of personae happens with a change of virtual place. Cycling through these virtual environments is made possible by the existence of what have come to be called 'windows' in modern computing environments. (Turkle 1999, p. 644)

'Multiple presences' in an online environment encourage a 'distributed self', which inhabits several virtual realms and performs numerous roles simultaneously. The actor similarly encounters these 'multiple presences' that encourage a 'distributed self' when engaging with his/her character and the action within the scene. Harrop and Epstein (1996, p. 7) elaborate on this notion of 'distributed presence' (Turkle 1999, p. 646) by highlighting the following:

[A] map of action...is broken down into modules of action that do not necessarily have to follow a simple narrative throughline, and that character is a complex of masks that equally do not have to contain a singular throughline and consistency. Discovering and playing action is not necessarily a rational process leading from points $\mathrm{A}$ to $\mathrm{B}$ to $\mathrm{C}$, but it can stem from a nucleus including point $\mathrm{A}, \mathrm{B}$ and $\mathrm{C}$, and not necessarily in that order.

Harrop and Epstein's ( 1996) notion of a non-lateral methodology to the discovery and understanding of action within the scene deepens Benedetti's ( 1981) method of character construction, the expanded self. By denoting the character's behaviour as a 'complex of masks' (1996, p. 7), Harrop and Epstein highlight that a specific action does not function in isolation. In order for the actor to understand and unravel the complexities of the character's behaviour, and thereby construct its identity, (s)he has to realise that a single action is not only influenced by its preceding action, but shaped by the collaboration of 'multiple [flexible] distributed "systems" of self' (Turkle 1999, p. 644) which are constantly in action. The Stanislavskian 'throughline of action' is hereby undermined and a seemly 'split-focused' actor's methodology for the construction and embodiment of the character and its identity (through action) is implied. This multifaceted approach may be linked to what Turkle refers to as 'an element of cultural bricolage', which implies a 
decentred identity developed through new social practices destabilising 'traditional, unitary notions of identity’ (Turkle 1999, p. 646-647; 2004, p. 5).

The 'windows' phenomenon has allowed for 'multiple presences', which encourages a 'distributed self' that inhabits several virtual realms and performs numerous roles simultaneously. This concurrency creates a decentred identity and allows for 'parallel lives' in both online and offline environments (Turkle 1999, 2004). In this regard, Del Rosso explains that, 'online identities are written into existence [self-authorship] and enable the individual to be more aware of what [they] project into everyday life [offline]' (2011, p. 718).

By juxtaposing elements of the actor's fictional personae construction process (Benedetti 1981; Harrop and Epstein 1996) with that of the virtual (mentioned above) and considering the tension between online and offline spaces, I questioned whether the virtual collusion/collision of the online and offline might not speak to the theatre actor performing a role or character, where text analysis might point to the character being at least partially constituted through repeating behaviour. This notion of repeating behaviour resonates with Judith Butler's comment that:

In the theatre, one can say, 'this is just an act,' and de-realize the act, making acting into something quite distinct from what is real. Because of this distinction, one can maintain one's sense of reality... [and claim] that 'this is only a play' [which] allows strict lines to be drawn between the performance and life. (Butler 1990, p. 278)

In bringing the offline into the online, cyberspace may have opened up new digital spaces and possibilities of self-identification and identity construction, where both online and offline notions of masculinity and sexual identity are reframed within a gay context. This acknowledgement of the possibility of occupying multiple positions (visible/invisible; participant/voyeur), as well as the body being the main site/sight of meaning construction, played a significant part in my design of the offline, physical theatrical space or 'set'. I came to envision a theatre space created to accommodate, encourage and demonstrate the collusion/collision of the cyber/physical, online/offline, virtual/visceral. This was done in order to explore and interrogate the ways in which virtual environments position and construct gay male identities, how sexual identities are framed in and through virtual practices, and the way in which gay men inhabit, represent and perform multiple masculine 'selves' via the interface between online and offline spaces.

Benedetti draws on the actor's social acting abilities and personal experiences of daily life and popular culture to create dramatic performances. In addition, it allows for character construction and transformation as related to given circumstances, allowing for the 'I' (the actor) and its several 'me's' (creating a character as an expansion of the 'self'). Benedetti (1981, p. 6) maintains that the actor should not turn his/her focus inwardly to the self, but rather focus on the self in action in the scene, thereby suggesting an outward focus. Here, Benedetti's concept of the 'I' (in terms suggesting a sense of continuity) and its several 'me's' crystallise in performance (1981, p. 6).

This study frames online actions as a mode/type of performance, and it is here that interrogating the behavioural action available to the webcam performer motivates an exploration of the possible parallels with Benedetti's ( 1981) emphasis on action and choice within the process of character creation and construction. Benedetti (1981, p. 197) points out that we are only able to understand 'a man's (character's) action by way of what he does, his outward and visible deeds' (1981, p. 197). Benedetti (1981, p. 197-231) further 
maintains that the choice to 'act' or not to 'act' is integral to understanding the character's behavioural responses to the given circumstances of the play. ${ }^{6}$ This allows the actor to channel the focus away from the 'I' and experience the self in action governed by the structures of the 'fictional world' as pertaining to the construction of the 'me's'. Benedetti's approach enabled the actors in owner's MANual to focus on how they were executing specific actions and performing behaviours. They realised that these actions formed part of a non-lateral methodology aiding the discovery and understanding of the character's identity as constructed through multiple and complex actions within the various scenes. They could observe these actions and behaviours by means of their own webcams. The 'I' of the actor (the continuous visceral 'I') that exists offline could inform the 'me' (addressing the expectations of the moment), who is performing the character that manifests online. Both 'I's' and 'me's' are located within the body of the actor which functions in both online and offline spaces of the installation performance. This is of great significance for the actor who has to discover 'playable actions' (Benedetti 1981, p. 196) by analysing and understanding the character's 'choice to act' (1981, p. 199).

These 'playable actions' shared with the audience as an 'outer phase of activity that is public and observable to your witnesses' (Benedetti 1981, p. 199) contribute to the understanding of the 'expressiveness of [the] character' (1981, p. 199), where expressiveness refers to meaningful repeated behaviours and actions that altogether constitute some measure of character. Similarly, it should be possible to interrogate the 'choice of action' within the 'moment of engagement' of the webcam performer, in order to explore his online construction as character creation as 'expanded self' (Benedetti 1981, p. 5) that is inserted and constructed virtually.

If technology (including online environments) can produce subjectivity, as Jones (2002, p. 950) suggests, and if 'doing' produces identity as Butler suggests, it follows that online activities could possibly impact on offline identity formation. Butler's and Jones's arguments further open up the notion that identity can be actively shaped by individuals and that the plural identities (and subjectivities) can exist and, indeed, co-exist.

\section{Ga(y)zing}

Shifting subject positions (and competing discourses) problematise, if not collapse, the dichotomy between subject and object. The subject, in this study, is both a product and a source of meaning, active ('subject of') and involved in, or produced by, a generative process (Macey 2000, pp. 368-369). Macey (2000, p. 279) explains that 'object' can refer to animate and inanimate things that generally relate to the satisfaction of needs, and can be read on physical, symbolical or metaphorical levels. 'Object' can function metonymically too, referring to a whole (for example, a body) or using parts of the whole (breasts, foot, penis) to suggest a whole entity beyond what is currently seen.

In virtual environments such as gay chat sites, the gay user is not just a passive object being looked at purely for the pleasure of the controlling active subject. He is a looking subject, but simultaneously an object being looked at. He is literally looking at himself while others are looking at him. He has simultaneously become subject and object within the same spatio-temporal moment. As he traverses the subject-object dichotomy, he straddles subject positions. Through the individual's activities in online spaces, he may regularly reposition himself - maybe to satisfy 'the narcissistic gaze of the subject' (Mowlabocus 2005) - by inviting this (re)construction: looking, beinglooked-at and looking-at-being-looked-at through discursive and performative practices (Chandler 2002, p. 45). The individual body becomes a shared, collectively 
(re)constructed visual text that gazes and is gazed at.

Through activities in the online space, the webcam performer may find alternative positions for himself (maybe to satisfy 'the narcissistic gaze of the subject' or 'the voyeuristic gaze of the Other' (Mowlabocus 2005) by inviting this (re)construction; looking; being-looked-at and looking-at-being-looked-at through discursive and performative practices (Chandler 2002, p. 45). The body, like identity and subjectivity, is in itself a social construct, an outcome of discursive practices fused with corporeality (Auslander, cited in Zarrilli 2002, p. 58). As such, the body is pre-inscribed with meanings, values and symbolism and it carries those pre-inscriptions into every space that it occupies. This juxtaposition of pre-inscription and stylised repetition of inscription positions the body as locus of experience, reading, subjectivity, performance, objectification and meaningmaking, of becoming.

As Culbertson $(1998$, p. 2) points out, the body is a 'textless text whose meanings are read by many readers, whether they are invited to read or not'. The body is not only a visual text, but a visceral text on which embodied meanings can be read, projected and experienced, with the other(s) (viewer, audience, spectator) and the webcam performer simultaneously being the reader and the author (creator) of this text, and vice versa. Looking at online environments such as chat sites, it seems that the gaze of the looking subject primarily focuses on the explicit body and sexual practices as framed through pornography. Mainstream commercial (and primarily Western) gay pornography has become so deeply imbedded in male gay consciousness that it has become the 'cultural framework through which sexual identity is produced, negotiated and maintained', shaping 'understandings of the Self and Other' in online and offline spaces (Mowlabocus 2007, pp. 64, 68). In order for the webcam performer (himself a looking subject) to be legible, to embody 'gayness' and to be viewed by a looking subject, he may select to conform to the traditional codes of the object. These codes and modes of behaviour are deeply imbedded within mainstream gay pornography.

\section{Pornification: from the expanded self to erect self}

Gay pornography promotes the stereotypical image of the butch white Caucasian male and ideal masculinity, excluding other identities and body types. As Mowlabocus (2007, p. 68) explains, '[w]hile the over-weight, the disabled, [the femme] and the nonCaucasian can and do inhabit...[these spaces], their inability - their failure - to conform to these pornographic ideals renders them illegible'. This illegibility fetishises these nonideal types. ${ }^{7}$ Gay online spaces allow for 'a kind of spectacularized gayness' (Foster 2001, p. 449). Virtual environments seemingly not only mimic stereotypical heterosexual masculinity, but also position gay men as objects in the economy of male desire: '[G]ay men are involved in the process of commodification of the self, at the very point in which they are creating themselves' (Mowlabocus 2005). Gay pornography on such sites appears to interpret the explicit body as the principal marker of gay sexual identity and engaging in/with pornographic acts confirms and affirms this identity. It would seem that virtual gay environments use the same tools through which marginalisation was created to name, self-define and represent being gay. Because the body becomes the sight/site for the interaction, the body becomes a platform on which pornographic fantasies and desires are played out. 
Jeffreys (2003, p. 78) recognises that '[p]ornography [is] crucial to gay men's survival, to their identities, and to their ability to do [perform] sex'. As pornographic representations of gay men are imbedded in the consciousness of the homosexual man, they inform the construction of his sexual identity as well as performance of masculinity. Adopting an 'exaggerated masculinity' located in gay pornography (Jeffreys 2003, p. 89) creates a sexualised and performed ideal gay body.

A framework of pornography - of framing and coding the body in performance in a pornographic, sexually explicit manner, and in terms of reading the male body as a phallic signifier of power and pleasure - enhances the understanding of the body as biological-social construct which is necessary when investigating notions of performance where the physicality of the male body is foregrounded. Cyberporn has become a particular formation of desire with an emphasis on the sexualised publication of desire 'across the male body at the points of its connection to technology' (Lillie 2002, p. 39). However, these technologies have also created a means for the individual to construct identity in relation to personal notions of desire as well as other Internet users' (gazers') pornographic desires. These interactive engagements take place in a socially constructed realm where multiple performances of the self are created and constructed in notions of bodily physicality and the pornographic illusion of the tangibility of the body, depending on the nature of the online communion.

Pornographic texts are being used for arousal and pleasure, but these experiences also serve to reinforce sexual and cultural identity for some, while serving to produce new and transitional identities for others. (Lillie 2002, p. 28)

Heim (as cited in Lillie 2002, p. 25) states that cyber technology's 'allure is more than utilitarian or aesthetic; it is erotic'. This eroticism manifests itself directly from the need to perform and give manifestation to pornographic desire; not only as a way to connect with the 'other' in the gay cyber collective, but in trying to free 'the self in the experience of the flesh' (Rabinow 1986, p. 339). This process of connecting with others and freeing the body from social and cultural restrictions allows the webcam performer to become a legible object functioning within the looking subject's pornographic desire.

Technologies such as the webcam serve, through the empowerment of selfobjectification, as an agent in the creation of a notion of the "pornstarification" ${ }^{8}$ of the individual. As stated earlier, the webcam performer emerges as the author of his own

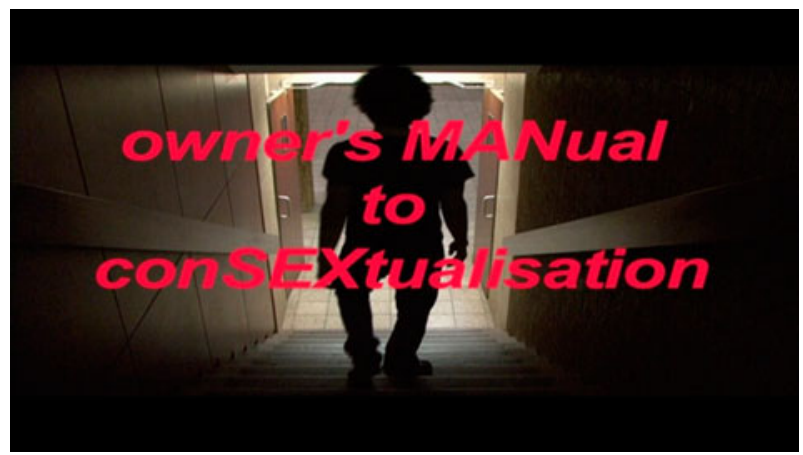

Figure 4. Pornography and ga(y)zing. 
online pornographic narrative. The webcam performer actively shapes the aesthetic and political/social agency of the implicit experience of pornographic engagement being looked at while aware of being looked at and returning the subject's gaze as a knowing object. This places the webcam performer at the centre of the virtual pornographic engagement by means of his construction of parallel identities (as subject and as object) through the performance of pornographic desire, as well as the embodiment of desired gay male masculinities and gay sexual behaviour.

The power gained by the object through the interactive engagement with the looking subject's pornographic desire enables immediate construction and performance of a 'desired' masculinity, which is in a constant state of flux. This speaks directly to Tuck's (2003, p. 263) notion of masculinity being acquired and shaped through an understanding of the nature of its existence and allowing for masculinity to be experienced and thus performed.

The construction being shaped by the needs and desires of the interactive 'moment' links directly to the manner in which the actor learns and prepares his/her character. The construction of the character is determined by the given circumstances of the play, provided by the playwright, as well as by the relationships and interactions with other characters, the milieu of the play and the audience's understanding of the visual text or performance. The theatre space is where the actor may observe himself/herself in action, seeing himself/herself in the act of seeing and recognising himself/herself within the same context but also to extrapolate to other contexts. His/her performance responds to the audience responding to his/her performance. It is a dynamic space where the actor and the spectator are willing to engage with the notion of looking at themselves - where all individuals become spect-actors (Boal 1995, pp. 13-15). This term refers to both parties (in Boal's context, the spectator and actor) actively participating in this process of creating themselves and the other, neither becoming just the object to satisfy a need, but also the subjects with abilities to act upon each other.

The individual is acutely aware of what is expected of his performance of gay masculinity in terms of what is desired, in many ways, from his performance. This increased awareness corresponds with that of the actor, who turns his attention to the particular demands of the play in terms of character expectation, which can further be investigated by considering Benedetti's ( 1981, p. 244-245) 'System of Fours'. This awareness of certain expectations and character requirements allows for character construction, which will enable the intended audience to recognise and engage with specific character traits.

Theatre (including performance), can offer a means of exploring the ways in which gay men inhabit virtual pornographic spaces by foregrounding the performance of pornographic desire; embracing multiple subject positions; inhabiting the interface between subject and object positions; drawing attention to the performance of masculinities, as well as the possible construction of a parallel online identity as part of a 'multi-distributed "system" of self' (Turkle 1999, p. 644). By means of online and offline performances within the production, (online) gay spaces were examined. The emphasis is on the way in which gay men inhabit these spaces to foreground, affirm and assert constructions of masculinity and sexual identity through virtual interactions. This virtual interaction resonates with notions of theatre, where theatre is a space where the acting subject observes himself in action, and is acutely aware of himself in the act of coding the body in a certain way, while seeing and recognising himself within a specific 
delineated context. In the theatrical space the performance responds to the audience responding to the performance.

I was able to explore and exploit the shifting subject-object positions in owner's MANual to conSEXtualisation by showing adjustments of the character's offline behaviour as a direct reaction to the online interaction with the other characters (all in looking subject positions, as well as performing the object). The construction of the theatre space allowed the audience access to both online and offline actions, which made them aware of the webcam performer's control of the online engagement by means of the visual construction of his body as mediated by the webcam. The character's webcam performer persona could manipulate the looking subject's execution of his controlling gaze, by choosing what (of), how and when he reveals his 'pornographic' body and thus 'acting' or 'performing' the looking subject's desired performance of masculinity. The characters whose webcam performer personas' bodies did not conform to the spectacularised gay male body depicted in gay cyberporn only revealed parts of the body (crotch, lips, tongue, feet) which would still draw the focus and attention of the collective towards their performance, still receiving their desired pornographic attention. Through the carefully selected construction of their parallel online personas, the characters could achieve their goal of successfully occupying the virtual pornographic space by adhering to the subject's pornographic fantasy. Because the webcam performer (persona) had visual access to both his own, the looking subjects and the audience's image via the technology, he was able to make clear deductions of how to effectively position himself to be looked at. By reading the online collective's requirements of the immediate moment of engagement, the webcam performer as knowing object was able to assume a persuasive subject position by becoming the author of his own personal pornographic narrative. The 'clues' he was receiving from the online collective functioned as the given circumstances within a dramatic text. He was able to use the givens, through self-objectification (pornographic visual construction of the body and its behaviour) to become the 'porn star' of his own pornographic narrative. The actors in owner's MANual to conSEXtualisation further actively focused on the multi-distribution of self, in order to facilitate the shifting of subject positions. In order to achieve continuity (from an actor-character point of view), they were required to approach both character construction (by means of Benedetti's 'expanded self' and 'System of Fours') and webcam performer creation (through the process of self-objectification) in a similar manner. Like the webcam performer, the actor (subject) needs to become a character (object) to be looked at by the audience (subject), through a process of self-objectification (actor's body), in order to allow an audience (subject) to read it for meaning. Character construction is determined by the desire to adhere to the demands of the script given by the playwright, which not only shapes the embodiment and behaviour of the actor (subject) as character (object), but also determines how the audience (subject) will 'look' and engage with the dramatic action on the stage.

\section{The actor and pornstarification}

In the online webcam chat site environment, as well as in owner's MANual to conSEXtualisation, spect-actorship and performativity enable the manifestation of the pornstarified, self-objectified, virtual (online) performer. The online gay chat site becomes a type of virtual theatre space, where the webcam performer, like the actor, has an opportunity to explore, construct and exhibit identity in much the same way as 
Benedetti considers character development and manifestation as part of the 'expanded self' (1981, p. 5) of the actor. This is where the assumed boundaries between offline and online narrative orders may become blurred and where re-imaginings of masculinity and sexual identity can be explored. This negotiation of fiction-reality and the reimagining and re-imaging of masculine sexual identity encompasses the body, performativity, identity and subject-object relationships.

Benedetti's ( 1981) approach to character construction may be directly linked with 'the pornographic desire of the moment', as previously mentioned. In the same way in which the actor works towards an extension of the self through the behavioural requirements of the scene, the webcam performer focuses on a pornographic version of the self, where online behaviour is constructed and shaped by the intended audience and demands of the online space and the fantasy. This pornographic characterisation is not necessarily behaviour integral to the core identity ('I') of the performer, but conceivable, and performable, due to the understanding of social role play ('me').

The existence of the pornographic creation of the webcam performer ('I') may then be seen as being part of his several 'me's'. Benedetti's ( 1981) views on characterisation, as well as Turkle's ( 1999) notion of a parallel, distributed self, led to a revisiting of Bert O. States' (2002) interpretation of Jiri Veltrusky's ( 1978) notion of two distinct discourses which separate the theatre and the play. These discourses happens simultaneously within the drama(tic) event, giving a solid framework to the experience of actor, character and audience (States 2002, p. 23). By placing Benedetti and Turkle's notions within the Veltrusky framework, the exploration of the similarities between the actor and the webcam performer's use of subject-object position relationships may be highlighted, in order to explain the construction of the actor and webcam performer's performance adhering to immediate desire.

States indicates that there is an indispensable personal pronominal order of all discourse [...] speaker (I), spoken to (you) and spoken of (he/it)' (2002, p. 23). This idea can be indicated in table form (see Table 1) and made applicable to a drama(tic) event:

This chart indicates the two separate but simultaneous discourses. The two separate discourses became the unifying factor within owner's MANual to conSEXtualisation and allowed for actor-character-webcam performer amalgamation. The actor adheres to strict rules of the installation-performance (theatre), but the character/webcam performer adheres only to the rules of the online engagement, fulfilling the need of the desire/ fantasy (play).

I came to the conclusion that this position of looking at a drama(tic) event can be extrapolated to the investigation of the context of the webcam performer and how it positions and frames the identity of the user and the interface between online and offline spaces, as well as how the individual inhabits these spaces. The amended table reads as follows (see Table 2):

Table 1. Pronominal order of discourse: actor-audience relationship.

\begin{tabular}{lll}
\hline THEATRE (Acting event) & & PLAY (Enacted event) \\
\hline Actor $=$ & I & $=$ Character \\
Audience $=$ & You & $=$ Other characters of self \\
Character $=$ & He (it) & $=$ Absent characters or events \\
\hline
\end{tabular}

Source: States (2002, p. 23). 
Table 2. Pronominal order of discourse: actor-character-webcam performer amalgamation.

\begin{tabular}{|c|c|c|}
\hline $\begin{array}{l}\text { OFFLINE (but online } \\
\text { engagement) }\end{array}$ & & ONLINE (but interface with offline) \\
\hline Individual $=$ & I & $=$ Performer \\
\hline Chat room collective $=$ & You & $\begin{array}{l}=\text { Performance (including the performer and collective } \\
\text { which participates) }\end{array}$ \\
\hline $\begin{array}{l}\text { Performer (online } \\
\text { performance) }=\end{array}$ & $\begin{array}{l}\mathrm{He} \\
/ \mathrm{It}\end{array}$ & $=$ Individual's fantasy / pornographic desire \\
\hline
\end{tabular}

Within the offline capacity the individual communicates to the chat room collective about who he is and what he wants them to understand about his presence in the chat room by carefully selecting what he is revealing to the intended audience (physically and textually placed in front of his webcam and computer) and thus making a definite statement about himself as webcam performer. This, as in theatre, adheres to the rules of the chat room and gives the individual control over his behaviour, actions and performance.

In the online capacity the performer adheres to the rules and conventions of the fantasy. He allows himself to become the object of sexual and pornographic desire (selfobjectification and seemingly forfeiting control) in order to fulfil his offline individual needs. The chat room collective is no longer in the role of audience, but rather participants in the fantasy as they contribute to this fictitious narrative together with the performer. The individual digitally embodies the performer on the screen and has hence transformed into an expanded self.

\section{Conclusion}

The difference between the actor and the webcam performer is that the webcam performer (individual) embodies all the pronominal positions in both discourses simultaneously. All individuals that stream their cams in the chat room occupy all the available and participating roles. This pertains to the destabilising of the traditional binary relationship between the subject and object. Through the notion of self-objectification, which speaks to the process of pornstarification, the object (subject) ('I') is manipulating the subject (object) ('You') to objectify the object (subject) ('I') through specific pornographic codes (sexual cyber role play behaviour) ('It') in order for the object (subject) ('I') occupy the subject position of porn star. ${ }^{9}$

In owner's MANual to conSEXtualisation the actors had to take their pronominal positions within both the Veltrusky chart and the amended chart into consideration. As multiple discourses were being grafted within the installation-performance, direct lines of communication, as illustrated in the Veltrusky chart, were intertwined with a do-ityourself approach to meaning making and the reading of the dramatic text. This method of DIY connotation and denotation destabilised the traditional subject-object relationships, aided spect-actorism and created the platform from which the possible connection between Benedetti's 'expanded self' and Turkle's 'distributed self' within offline and online identity construction, as well as between the actor-character and characterwebcam performer relationships, could be explored. 
This study demonstrated how a process of character construction for theatrical performance may inform the performance of the webcam performer. It further highlighted the notion of a collaborative actor-character-audience engagement as central to meaning making via theatrical discourse in owner's MANual to conSEXtualisation. This engagement would be characterised by the relationship between the looking subjects' pornographic desire and the creation of the performer's object position.

In the installation-performance the concept of 'audience' diverged from its traditional theatre connotation. As explained in the amended chart above, all pronominal positions within the discourses were inhabited by the participants in the theatre exchange and they had the capability of re-positioning, depending on the nature of the immediate interaction. These shifting of positions were not only possible during the actor's webcam performer persona's online engagements, but also for their characters, due to the dishevelled nature of the communication. Similar to the actual webcam performer's online engagement with the virtual collective (or audience), the stage actor's relation to the audience may be considered 'as a "we" voice in the sense that the audience joins the actors in the stage enterprise' (States 2002, p. 29). The role of the audience in owner's MANual to conSEXtualisation, as a looking subject (but also technologically mediated themselves), influenced the actors' approach to the construction of their characters and the webcam performer personas. The link between the character construction and that of the shifting subject-object positions of the webcam became evident. Because multiple 'active' audiences were present and had access to both online and offline manifestations of the characters' identities, all characterisation had to take place via self-objectification in order to allow the object (character and webcam performer) to create a specific position from which to be looked at. This allowed not only for meaning to be invited onto his body by the looking subject, but for him to create meaning by allowing his body to be read by the looking subject within the paradigm of the immediate engagement. For the webcam performer this translates to 'pornstarification', which implies the notion of selfauthorship. This self-authorship for the actor is characterisation. Performances are shaped by given circumstances (stage/offline) and the pornographic desire of the moment (virtual/online). In owner's MANual to conSEXtualisation the actor's 'expanded self' extrapolated online space as his 'distributed self'.

\section{Notes}

1. 'I' as used in this article to indicate the director of owner's MANual to conSEXtualisation refers to Rian Terblanche specifically.

2. Specific reference to primarily Mand8, Cam4, Flirt4free, Gaydar, as well as Skype - a proprietary software application that allows users to make video calls over the Internet. Also, as this study focuses on the homosexual man, it only refers to the 'gay male'. Any other taxonomies based on sexuality, gender or sex therefore fall outside the scope of this study. The cast of owner's MANaul were male and female and so s/he and /his/her will be used where appropriate.

3. Turkle's use of the personal pronoun.

4. It is important to note that Boal's context, use and purpose of this term differs from its application to this study. For the purpose of this study, although Boal's notion of the spect-actor does not focus on traditional theatre and acting, the notion of the spect-actor wants to liberate the 'one who looks' (the spectator) from 'passive victim[hood]' (2000, p. 155), it sheds light on the dialectic relationship between actor and spectator in terms of the constructions and meanings of the performance. In his Poetics of the Oppressed (2000, pp. 120-155), Boal strives toward equal power distribution amongst actor and audience. In owner's MANual to conSEXtualisation, this 
sharing of 'power' led to all spect-actors becoming part of the creative processes involved in making theatre and constructing performance(s). This negotiation of fiction-reality and the reimagining as well as re-imaging of masculine sexual identity encompasses the body, performance of masculinities and subject-object relationships. By applying Boal's notions to the theatre inquiry space, it was possible to investigate the tension between traditional and alternative modes of looking and utilising subject-subject looking relations to examine how owner's MANual to conSEXtualisation positioned, constructed and performed gay (online) masculinities, as well as the cultural legibility of this, at the intersection of virtual and visceral environments.

5. Fictional refers to the actor creating/constructing a character in a physical offline space (e.g. the theatre) and virtual pertains to constructions within an online environment.

6. The given circumstances may be related to the expectations of the moment of the webcam performer's online engagement. Just as the given circumstances determine the actor's choices of behaviour/action available to character construction, the online engagement is governed by specific expectations determined by the rules and regulations of the chat site, as well as the expectations of the online collective. The collective refers to all the individuals participating in the immediate online engagement (users of the particular chat site). This engagement creates a certain virtual sexual togetherness, which may be seen as a type of cyber intercourse governed by the rules of participation. It speaks to performativity (Butler) and spect-actorship (Boal).

7. Interestingly, mainstream systems of representation, like Hollywood film, have a history of positioning the male body as fetish (Ward 1998, p. 1). Action films, for example, spectacularise male bodies as primary signifier of 'masculine potency' and a representation of 'phallic power' for consumption by a heterosexual audience (Ward 1998, p. 1).

8. This term is derived from Paasonen, S. et al., eds. (2007) Pornification: sex and sexuality in media culture. This implies that an individual has the power and control to be the centre of his own pornographic online creation and performance, and that this manner of narrative construction creates a type of 'star system' for, and gives 'top billing' to, the performer within the various webcam chat sites. Similar terms have been encountered in, especially, online writings, serving mainly as caption for images of celebrities; never used in the context of interactivity.

9. These positions are constantly shifting and embodied by all participants in the two discourses.

\section{References}

Bargh, J.A., McKenna, K.Y.A., and Fitsimons, G.M., 2002. Can you see the real me? Activation and expression of the 'true self' on the internet. Journal of Social Issues, 58 (1), 34-48.

Benedetti, R.L., 1981. The actor at work. Boston, MA: Pearson Allyn and Bacon.

Boal, A., 1995. The rainbow of desire. London: Routledge.

Boal, A., 2000. Theatre of the oppressed. London: Pluto Press.

Butler, J., 1990. Gender trouble: feminism and the subversion of identity. London: Routledge.

Chandler, D., 2002. Semiotics for beginners. Available: http://www.aber.ac.uk/media/Documents/ S4B/semiotic.html. [Accessed on 22 October 2010].

Culbertson, P., 1998. Designing men: reading the male body as text. Journal of the Society for Textual Reasoning, (7). Available from: http://etext.virginia.edu/journals/tr/archive/volume7/Culbertson1. html [Accessed 7 July 2010].

Del Rosso, J., 2011. The penis as public part: embodiment and the performance of masculinity in public settings. Sexualities, 14 (6), 704-724. Available from: http://sex.sagepub.com/content/14/ 6/704 [Accessed 15 April 2012].

Fels, L., and Meyer, K., 1997. On the edge of chaos: co-evolving world(s) of drama and science. Journal of Teacher Education, 9 (1), 75-81.

Fels, L., 1999. In the wind clothes dance on a line: performative inquiry - a (re)search methodology. Possibilities and absences within a space-moment of imagining a universe. Dissertation $(\mathrm{PhD})$. The University of British Colombia. Vancouver, Canada. [O]. Available from: http://www. nursing-informatics.com/PhD/LynnFels_dissertation.pdf [Accessed 27 August 2010].

Foster, T., 2001. Trapped by the body? In: D. Bell and B.M. Kennedy, eds. 2000. The cybercultures reader. London: Routledge, 439-459. 
Govan, E., Nicholson, H., and Normington, K., 2007. Making a performance: devising histories and contemporary practices. New York: Routledge.

Harrop, J., and Epstein, S.R., 1996. Basic acting: the modular acting approach. Boston, MA: Pearson Allyn and Bacon.

Jeffreys, S., 2003. Unpacking queer politics: a lesbian feminist perspective. Cambridge: Polity Press.

Jones, A., 2002. The 'eternal return': self-portrait photography as a technology of embodiment. Signs: Journal of Women in Culture and Society, 27 (4), 947-978.

Kibby, M., and Costello, B., 1999. Displaying the phallus: masculinity and the performance of sexuality on the internet. Men and Masculinities, 1 (4), 352-364. Available from: http://jmm. sagepub.com/content/1/4/352.full.pdf + html. [Accessed on 15 April 2012].

Kibby, M., and Costello, B., 2001. Between the image and the act: interactive sex entertainment on the internet. Sexualities 4. Available from: http://sex.sagepub.com/content/4/3/353 [Accessed 7 April 2012].

Lee, C.I., and Gura, T., 2009. Oral interpretation. Boston, MA: Houghton Mifflin Company.

Lillie, J.J.M., 2002. Sexuality and cyberporn: towards a new agenda for research. Sexuality and Culture, 6 (2). Available from: http://0-search.ebscohost.com.innopac.up.ac.za/login.aspx?direct $=$ true $\& \mathrm{db}=$ hlh $\& \mathrm{AN}=7171087 \&$ site $=$ ehost-live \&scope $=$ site [Accessed 14 August 2010].

Macey, D., 2000. The Penguin dictionary of critical theory. London: Penguin Books.

Matsuba, M., 2006. Searching for self and relationships online. CyberPsychology \& Behavior, 9 (3), 275-284.

McGaw, C.J., 2011. Acting is believing: a basic method for beginners. Whitefish, MT: Literary Licensing LLC.

Mowlabocus, S., 2005. Being seen to be gay: user profiles and the construction of gay male identities in cyberspace. In: G. Simon and K. Burkitt, eds. Future of identity. Working papers in contemporary history and politics no. 30. Manchester: European Studies Research Institute.

Mowlabocus, S., 2007. Gay men and the pornification of everyday life. In: S. Paasonen, K. Nikunen and L. Saarenmaa, eds. Pornification: sex and sexuality in media culture. New York: Berg, 61-72.

Murray, C.D., and Sixsmith, J., 1999. The corporal body in virtual reality. Ethos, 27 (3), 315-343. Available from: http://www.jstor.org/discover/10.2307/640592?uid=3739368\&uid =2\&uid= 4\&sid $=56230031183$ [Accessed 20 March 2012].

Paasonen, S., Nikunen, K., and Saarenmaa, L., eds. 2007. Pornification: sex and sexuality in media culture. New York: Berg.

Rabinow, R., 1986. The Foucault reader. New York: Random House Inc.

States, B.O., 2002. The actor's presence: three phenomenal modes. In: P.B. Zarrilli, ed. Acting (re) considered. London: Routledge, 23-39.

Tuck, G., 2003. Mainstreaming the money shot: reflections on the representation of ejaculation in contemporary American cinema. Paragraph, 26. Available from: http://www.euppublishing.com/ doi/abs/10.3366/para.2003.26.1-2.263?journalCode=para [Accessed 24 July 2010].

Turkle, S., 1994. Constructions and reconstructions of self in virtual reality: playing in the MUDs. Available from: http://web.mit.edu/sturkle/www/constructions.html [Accessed 15 April 2012].

Turkle, S., 1999. Looking toward cyberspace: beyond grounded sociology. Contemporary Sociology, 28 (6), 643-648. Available from: http://www.jstor.org/discover/10.2307/2655534? uid $=3739368 \&$ uid $=2 \&$ uid $=4 \&$ sid $=56230031183$ [Accessed 18 March 2012].

Turkle, S., 2004. Collaborative selves, collaborative worlds: identity in the information age. In: J.A. Inman, ed. Electronic collaboration in the humanities: issues and options. Mahwah, NJ: Lawrence Erlbaum Associates.

Turkle, S., 2005. The second self: computers and the human spirit. Twentieth anniversary edition. Cambridge, MA: MIT Press.

Veltrusky, J., 1978. Contribution to the semiotics of acting. In: L. Matejka, ed. Sound, sign and meaning: Quinquagenary of the Prague Linguistic Circle. Ann Arbor, MI: Dept. of Slavic Languages and Literatures, University of Michigan, 553-606.

Ward, G., 1998. Hung like a horse: male stripping in recent films. Journal of the Society for Textual Reasoning, (7). Available from: http://etext.virginia.edu/journals/tr/archive/volume7/Culbertson1. html [Accessed 4 July 2010]. 
Weedon, C., 2004. Identity and culture. Berkshire: Open University Press.

Zarrilli, P.B., ed. 2002. Acting (re)considered. A theoretical and practical guide. Second edition. London: Routledge.

Chat sites

http://www.cam4.com

http://www.flirt4free.com

http://www.gaydar.co.uk

http://www.mand8.com

http://www.skype.com 